\title{
Good Coal and Poor
}

\section{Purchase of Coal on the Basis of Its Heating Value}

\section{By J. A. Holmes, Director of the United States Bureau of Mines}

FOR many years the "unbusiness-like" farmers of F this country have been purchasing their fertilizers on the basis of the percentages of the available nitrogen, or potash, or phosphate each contained, while the "business men" have long continued the purchase of coal for their factories and residences on the basis of its looks or its general reputation.

But during the past few years the fuel resources of the country have been investigated more carefully than ever before, and with special reference to the development of methods by which the different kinds of coal can be used with greatest efficiency, and can be purchased on a basis fair alike for the producer and consumer. As a result of this movement for greater fuel efficiency, the general government, the larger cities, and the larger manufacturing, power, and lighting companies of the country are now purchasing their coal on the basis of its heating value, as indicated by chemical analyses.

\section{COAL AND ITS COMPOSITION.}

Few materials so extensively used are at the same time so little understood as is coal. The dictionaries define it; the geologists describe its origin from vast accumulations of vegetable matter, and tell us how under different conditions during past ages this vegetable matter has been transformed into different types of coal. The chemists show this coal to be com. posed mainly of carbon, hydrogen, and oxygen, with smaller quantities of nitrogen, sulphur, and other mineral substances: But the meaning of this information in the language of fuel efficiency is another and more intricate proposition.

The chemist reports the results of his examination in a form illustrated by the following analyses of four types of coal. The first column of figures (a) represents a good anthracite coal; the second (b) a highgrade bituminous coal (Pocahontas); the third (c) a low-grade bituminous coal, and the fourth (d) a typical Northwestern lignite.

Analyses of Types of Coal.

\begin{tabular}{|c|c|c|c|c|}
\hline & (a) & (b) & (c) & (d) \\
\hline & $\begin{array}{l}\text { Anthracite } \\
\text { (Furnace } \\
\text { Coalo of } \\
\text { Good } \\
\text { Quality). }\end{array}$ & $\begin{array}{c}\text { High Grade } \\
\text { Bitum L } \\
\text { nond Coal } \\
\text { (Poca- } \\
\text { hontas). }\end{array}$ & $\begin{array}{l}\text { Average } \\
\text { Low Grad } \\
\text { Bitumi- } \\
\text { nous Coal. }\end{array}$ & $\begin{array}{c}\text { North } \\
\text { Dakota } \\
\text { Lignite. }\end{array}$ \\
\hline 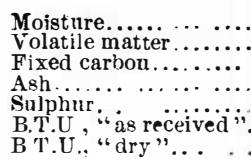 & $\begin{array}{r}3.33 \\
3.27 \\
84.28 \\
9.12 \\
9.12 \\
0.60 \\
18.351 .00 \\
13.810 .00\end{array}$ & $\begin{array}{r}2.8 \\
18.0 \\
73.9 \\
5.3 \\
0.64 \\
0.64 \\
14,950.00 \\
14,970.00\end{array}$ & $\begin{array}{r}10.83 \\
36.24 \\
39.75 \\
13.18 \\
4.53 \\
10,816.00 \\
12,130.00\end{array}$ & $\begin{array}{r}36.13 \\
29.28 \\
29.55 \\
5.04 \\
0.59 \\
7,326.00 \\
11,473.00\end{array}$ \\
\hline
\end{tabular}

INTERPRETATION OF COAL ANALYSES.

The owner of a large manufacturing establishment, who for the first time is presented with a bunch of such analyses, and finds his coal bill accompanied by a bill to cover the cost of these analyses, naturally inquires what it all means. The following notes may be of service to him.

The moisture; this may be partly inherent in the coal and partly external from the snow, rain, or dew, but in any case it appears to have no heat value, and the less of it he has to pay for the better.

The volatile matter is not fully understood; it is given off as gases in the early stages of the burning; it is known to be of real value, and furnishes the lon flame so useful under certain conditions, though a varying proportion of this volatile matter appears to be inert, and of no heat producing value. Some of it is lost in burning, and its loss is intimately associated with the smoke nuisance in all our cities, to escap which, as this volatile matter is greater or less, we must use one or another of the different types of mechanical stokers. The analysis of the coal aids in de termining the type of stoker best adapted to its etficient burning, but generally there must be supplemental tests in the furnace before a definite conclusion can be reached.

The fixed carbon represents the chief fuel value of the coal, as the process of combustion is largely the development of heat through the oxidation of this carbon and a portion of the hydrogen and carbon in the volatile matter through their combination with the oxygen of the atmosphere introduced through the draft.

The ash is a necessary but useless nuisance; and when it melts or forms a slag on the grate bars, as it is especially apt to do when high in iron, lime, and other alkalies, it becomes a troublesome nuisance by seriously interfering with the draft and efficient burn ing of the coal. Therefore, other things equal, every one prefers a low-ash coal, and especially one with an ash that does not slag readily in the furnace. Thi preference is not lessened by the fact that the chemist cannot fully explain either why the ashes of certain coals slag more seriously than those of other coals, nor how this evil can be satisfactorily prevented or counteracted in the furnace.

The sulphur found in coal usually occurs in the form of iron pyrites, sulphate of lime, alumina and magnesia, combined with hydrogen and carbon, or free sulphur. In best coals it is usually less than one per cent. In lower grade coals it occasionally constitutes as much as five or six per cent of the total weight. It is usually regarded as objectionable, but weight. It is usually regarded as objectionable, but
rarely proves seriously injurious to the boiler tubes unless accompanied by considerable quantities of moisture. When combined with iron (in pyrites), it is chiefly objectionable because of its tendency to fuse or form a slag on the grate bars which may seriously interfere with the draft, and, therefore, with the efficient combustion of the coal.

But the tendency of the chemist of to day is to pass over all the above vexatious and unsettled problems, and explain to the layman that the British therma units (B.t.u.'s) represent the real fuel value of the coal-though they do not always accurately do so. A
"B.t.u." is a heat unit. or the quantity of heat required to raise a pound of water one degree in temperature (from $39 \mathrm{deg}$. to $40 \mathrm{deg}$. F.). The heat unit used in countries other than Great Britain and the United States is called a calorie, and represents the quantity of heat required to raise a gramme of water one degree in temperature (from zero to $1 \mathrm{deg}$. C.).

HOW THE BRITISH THERMAL UNITS ARE DETERMINED.

In the analyses given above, the anthracite coal is described as containing 13,351 B.t.u.'s "as received," or 13,810 B.t.u.'s "dry coal" (dried at 105 deg. F.). This means that each pound of this anthracite coal "as received" contained 13,351 British thermal units, or that a ton $(2,000$ pounds $)$ would contain 26,702, 000 B.t.u.'s. The number of these thermal units in any given coal may be calculated from its chemical composition; but it is usually determined in an instrument called a calorimeter; and the calorimeter now generally used in the United States is the EmerWilliams modification of the Mahler, or Mahler-Berthelot bomb calorimeter. The Emerson type of this calorimeter and the method of using it are illustrated in the accompanying photographs.

One gramme of finely pulverized coal is burned in this calorimeter in the presence of an excess of pure oxygen. The coal is ignited by the electric heating of a small platinum wire passing through the coal placed on a tray within the calorimeter. The bomb of the calorimeter is immersed in a given volume of water. The increase in the temperature of this water due to the burning of this one gramme of coal is accurately measured by a thermometer, read through a telescope by the observer, who remains a sufficient distance from the calorimeter to prevent its temperature being affected by the warmth of his body.

PURCHASE OF COAL ON SPECIFICATION.

Under the old method of purchasing coal it was usually prescribed that the coal should be that usually sold under a certain standard trade name, or "as good as" that standard coal, and "free from slate." But there was no means provided for the measurement of slight, or even serious, variations from this standard, except as these variations might become apparent to the eye.

In the purchase of coal on specifications, by means of chemical analyses, even slight variations in the quality of the coal are easily detected, and corresponding variations in its value easily determined.

A rational plan of procedure is as follows:

In the establishment of a new power plant for manufacturing, lighting, or heating purposes, the furnaces installed should be selected with special reference to the efficient burning of the coals locally available; the engineer in charge then issues a description (including chemical analyses and B.t.u.'s) of the standard of coal he desires to purchase for his plant, and asks for bids on the basis of this standard, un(Continued on page s88.)

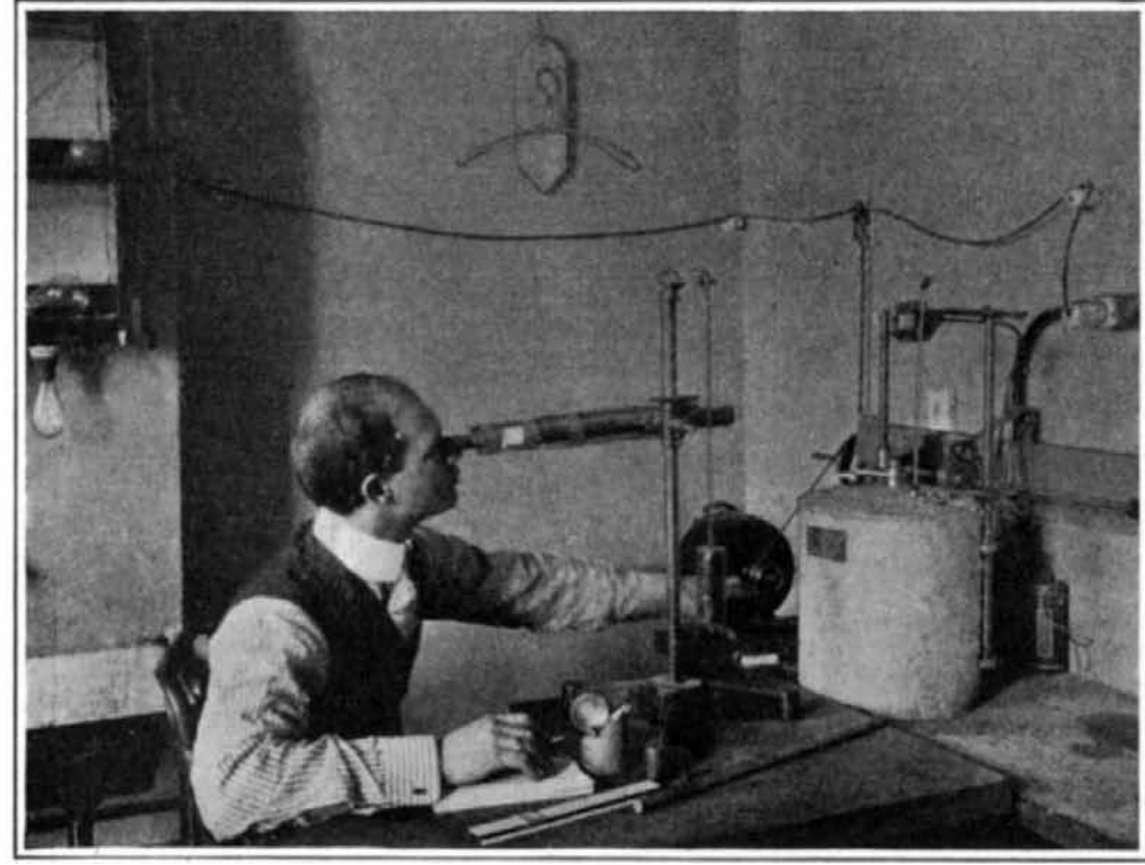

An observer watching the rise in the temperature of the water surrounding the "bomb" of a Mahler-Emerson calorimeter, in which "bomb" one gramme of dry, pulverized coal has been burned.

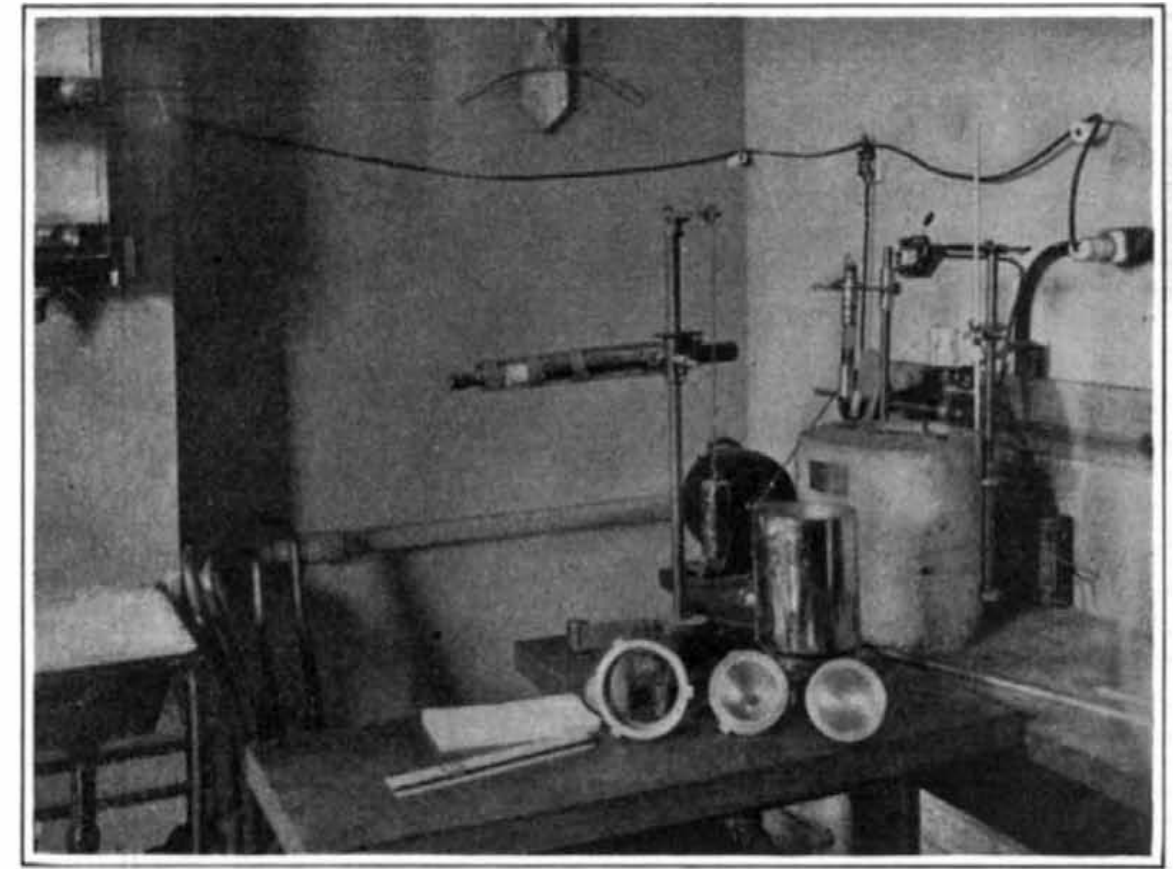

The Mahler-Emerson calorimeter, showing the "bomb" open on the table. Back of this is the metallic vessel in which the "bomb" is immersed in water. The vessel is placed inside a felt-covered casing. The water is stirred and its temperature measured. 


\section{nelsonis PERPETUAL RelsOnS LooSE-LEAF Encyclopaedia and}

Research Bureau for Special Information

\section{Four Great Achievements}

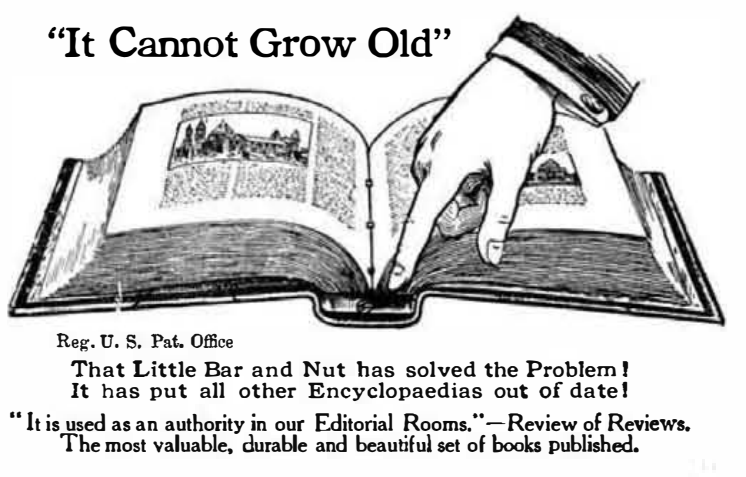

1. Patented Loose-Leaf Binding Devico

2. Three Permanent Staffs of Editors Insure accurate and dependable in-

3. Research Bureau to Answer Question Makes Nelson's the only complet
work of refern nce.

Models and ManikinsShow andExpla Human Body, etc.
Huble, Turber Approved, adopted, and used by the school Boards throughout the coun a Canada.

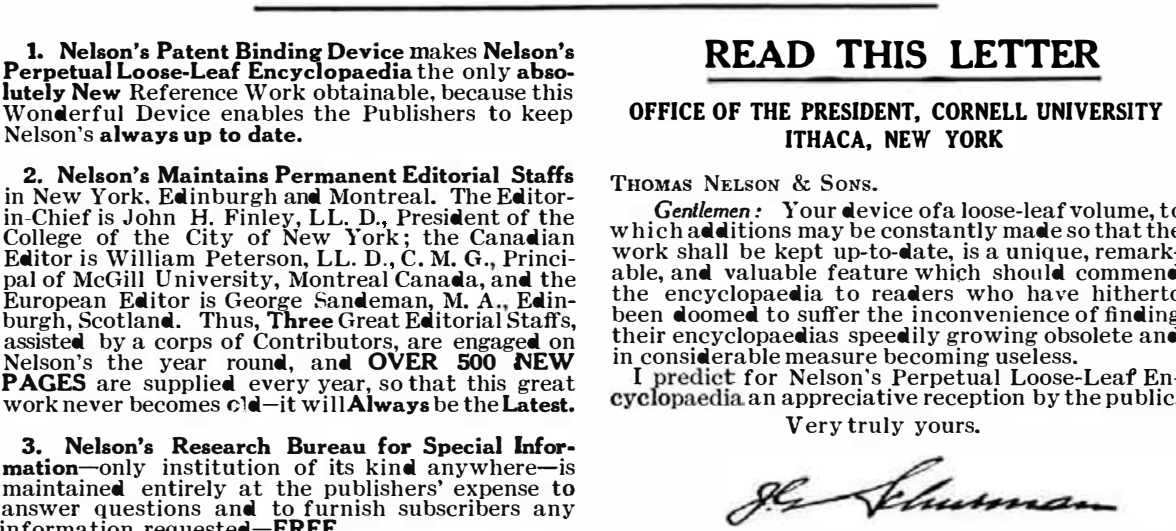

4. Nelson's Beautiful Models and Manikins have NELSON'S PERPETUAL LOOSE-LEAF ENCY such absorbingly interesting subjects as the Human SUBJECTS-TREA TING OVER 1,000,000 TOPIC

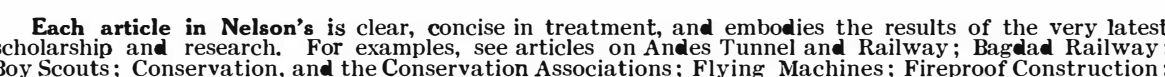
Foods; Industrial Education; Inland Waterway; Motor Boats and Motor Cars; Panama Canal (constructiv
work, concrete plans, etc.) : Portugal as a Republic; Submarines and Submersibles; and hundreds of other
not to be found in any other Encyclopaedia. EXCHANGE Write today for the FREE loose-leaf portfolio on Nature Study, particulars of the Bureau of Reseat
. F THOMAS NELSON \& SONS, DEPT. 381-385 Fourth Ave., New York Founded in Edinburgh 1798 OVER 100 YEARS IN BUSINESS Established in New York 185

đ A HOME-MADE 100-MILE WIRELESS TELEGRAPH SET VIE grams accompany the text. Price, 10 cents, by mail. Orderfrom yournewsdealer or $\mathscr{S C} C u n n$ \& Co., Inc., 361 Broadway, N.Y.

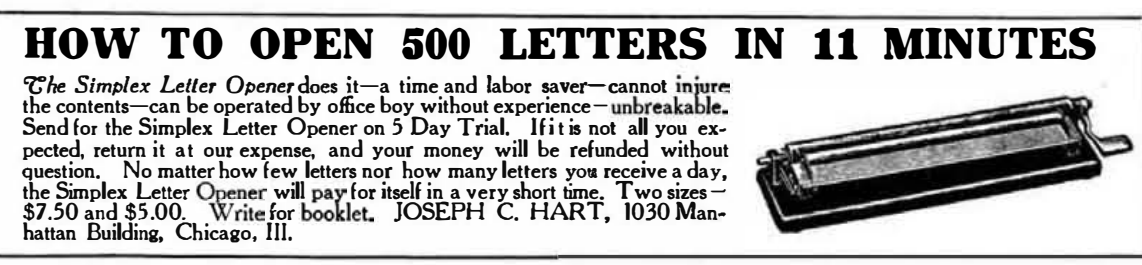

The electric vehicle is infinitely more simple to take care of and to operate and far less expensive to maintain than a gasoline car-and

\section{The Edison Storage Battery}

has made it an absolutely practical car that will go anywhere that a gasoline car will go.

Whether you are considering a

out Edison Storage Battery equipment. pleasure vehicle or a commercial car, The Edison has given the electric do not' make your decision until you trics" thoroughly.

Do not consider an electric vehicle, Storage Battery field in which you Do commercial, with- are interested.

Edison Storage Battery Co., 132 Lakeside Ave., Orange, N. J.
Light and Shadows

(Continued from pase s75.)

gotten from the several views of rooms lighted by these fixtures shown herewith. The simple style of fixture is well Shown in the illustration of the offices of the Hamilton National Bank of Chicago. Here the ceilings are ivory with gold aecorations, and the walls are white en-
mel down to the wainscoting, which is marble.

In the home we generally want brigh light only over a small space such as the reading chair, the dressing table or the suffices in other parts of the room. Even when a whole room is to be lighted a ozy, restful illumination is more easily bained by a number of smanl lamps it is preferable to avoid glare by use of shades rather than by indirect lighting. n some cases, however, as for instance the number of outlets is limited, may be advisable to use a single large high-eficiency lamp in an indirect light If the ceilings and walls are light colored and a good reflector is used, one 100-watt lamp will light a room fifteen feet square or smaller fairly vell; if more outlets fect is obtained by using a somewhat smaller lamp for the indirect fixture, supplementing it with one or two small direct lights.

While most of us have a predilection for the shaded direct lamp, illumination and it must bergely a matter of taste, ing results can be obtained by indirect ighting in the home. Light walls are y neans indispensable; for example, 22 feet, the walls and hangings are ark green, yet the two-light fixture gives be read with by which fine print can room given is an extreme case in that all the finishing except the panels of the ceiling is very dark. Even here four 60 watt lamps

In the second living room shown, which is $15 \times 23$ feet, the bowl fixture contains six 40 -watt lamps, arranged so that either two, four, or all six may be used.

In an be made to excel either the cove or the "direct-indirect," and while it is gineer's sense of the word, than wellplanned direct lighting, the power consumption is by no means excessive. As an example, the new building of the
Portland (Oregon) Railway, Light and Power Co., where the ceilings are ivory and the walls a light tan, is satisfactorily ighted throughout with this system with an expenditure of 1.1 to 2.5 watts per square foot, which would be a rather his sort if lighted directly with good arbon lamps.

In the Hamilton National Bank the indirect system is not merely more satisfactory, but actually uses 30 per cent less In conclusion it may be said that the problems of illuminating engineering are far from solution, and opinions differ widely as to the relative merits of var ous plans and devices. It would be premature to assign to indirect lighting a definite rank, but it is certainly worthy of serious consideration for its artistic possibilities and as a long step forward in the movement toward the conservation in the moveme
of eyesight.

Good Coal and Poor (Continued from page sz6.) der the condition that if the coal delivered is above the standard, the seller of the coal receives a premium, and if below the standard, the seller of the coal pays a penalty, in proportion.

In some cases the standard is based pon the number of heat units alone; in per cases upon the heat units and the ercentage of ash; in still other cases the heat units, percentage of ash, volatile sidered. A desirable tendency is toward simplifying the specification, basing it upon the heat units alone, but providing that if the heat units fall below a certain
figure, or if the ash forms a serious slag figure, or if the ash forms a serious slag
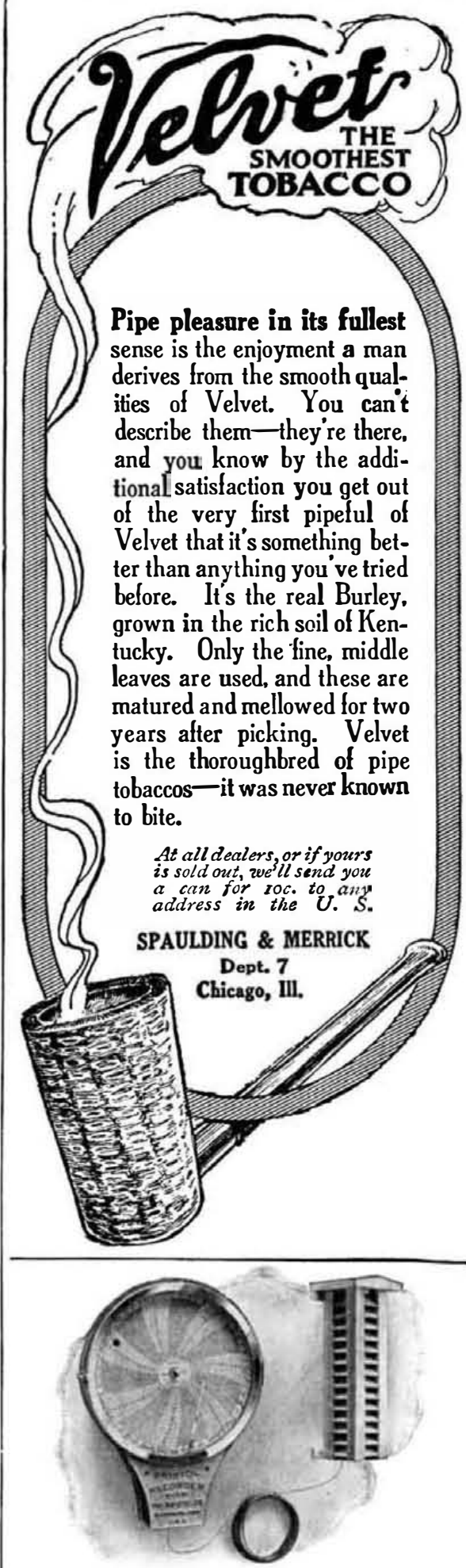

BRISTOL'S RECORDING THERMOMETERS

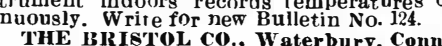

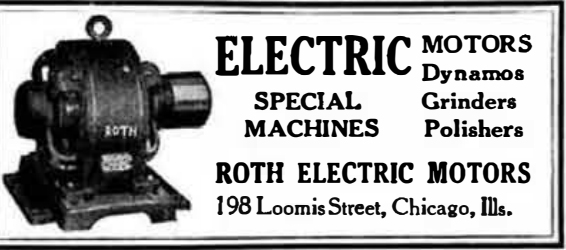
CRUDE ASBESTOS PREPARED R. H. MARTIN, ASBESTOS FIBRE OFFICE. ST.PAUL BUILDING

Two Cents a Week Pays Wash Bill!

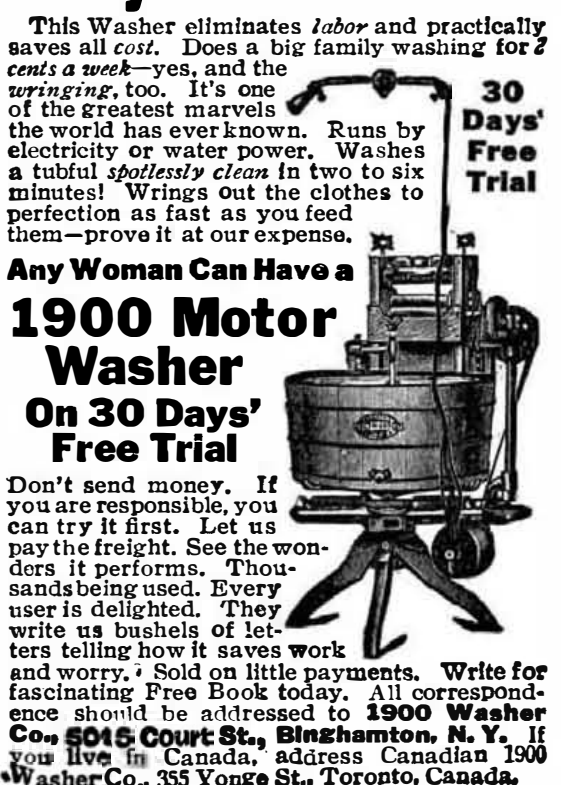


When Your FingerTip Taps the KeyWhat Happens?
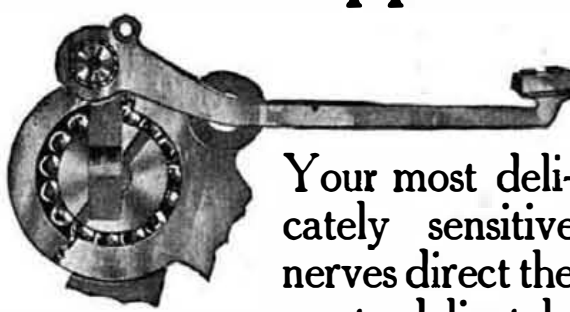

Your most delicately sensitive nerves direct the most delicately responsive mechanism of the L. C. Smith \& Bros. Typewriter

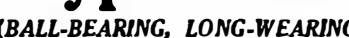

Key-lever, typebar, carriage (and shift, if you write capitals) - really all essential operating parts of the typewriter-leap into action and perform their functions with the perfect ease, smoothness and absolute precision of ball-bearings, made and adjusted with scientific exactness.

The nerves of this typewriter are sensitive to the nerves of your finger-tips, and just as instantly responsive as the finger-tip are to the brain.

This immediate, smooth, sympathetic action duplicated in no other writing machine, is easiest for the operator and most advantageous to the machine. Both wear longer. Send for Descriptive

Literature
L. C. SMITH \& BROS.

TYPEWRIER CO.
Head Offe for Domestic
ond Foreign Business
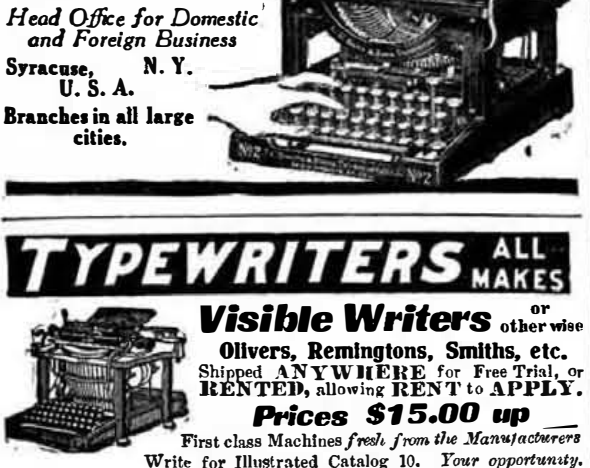

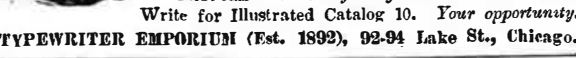

Typewriter TYPE and Type Makin writers and Other Machines Using Steel Type NEW YORK STENCIL WORKS, 100 Nassau St., N.Y.

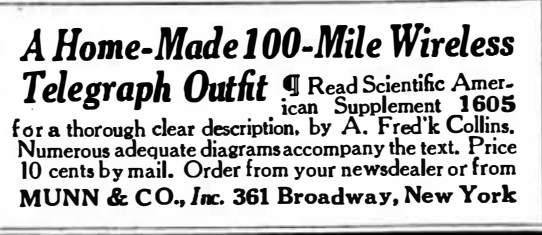

Let the Red Devil Water Motor Do Your

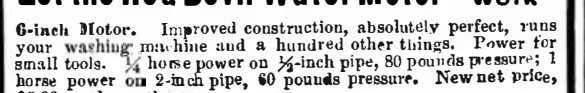

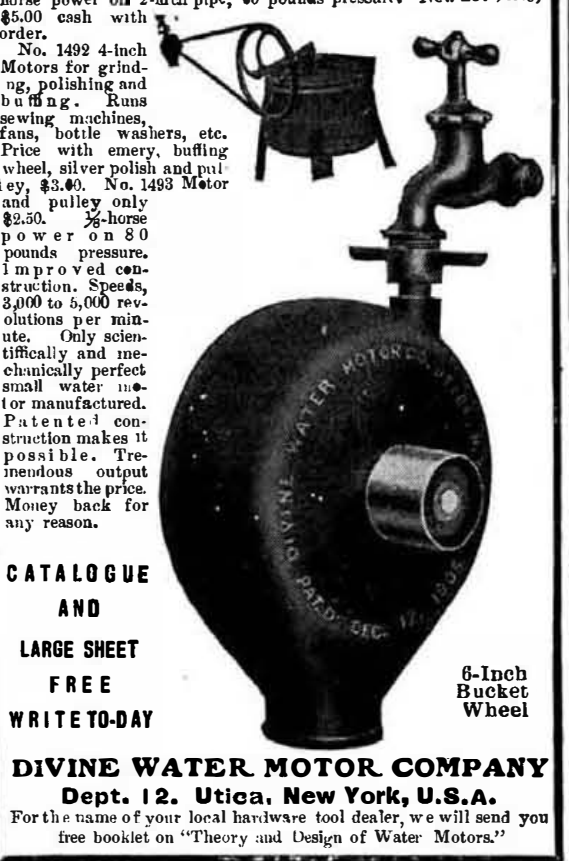

badly and beyond reasonable remedy, the contract will be canceled.

There are certain difficulties in the way that retard the general adoption of such a specification in the purchase of coal The most serious of these difficulties is the collection of a fair sample of the true where the sample must be collected from coal already loaded in cars, on board ships, or stored in large bins. In these and in other cases the collection of fair sample is more difficult than the making of an accurate analysis; but it is also important that in the work of the chemist only standard equipment and
standard methods should be used-and by experienced chemists.

In endeavoring to predict from chemical analysis (B.t.u.'s) the efficiency with which a given coal will burn in the furnace, the greatest factor of uncertainty is the behavior of the ash; slag on the grate bars. Another facto of uncertainty is the behavior of the coal itself; whether it will cake on the uppe surface in burning sufficiently to interfere with the draft (and the combusWhen our knowledge concerning this and other less important matters is ad vanced sufficiently, instead of purchasing coal as we now do at a given price per ton, we will be able to purchase it on the basis of a given price per one thou the heat units.

Heating the Home

\section{(Continued from page s78.)}

pense and insure successful operation. Consider the climate of the locality, the temperature, whether mild or extremely detached or in an exposed position, the size and height of the chimney, the height of the cellar ceiling, the amount of glass or window exposure. Allowances should be made for loosely fitting windows, etc. Finally consider the fuel at hand. Tabulate these details and submit them to the heater manufacturer. If it is a small compact house of one or two stories (any climate) the hot air furnace will provide ample heat and prove satisfactorily economical and lowest in cost of installing. It has much to commend it for this class of heating. It is simple with practically nothing. to go wrong, and the repairs are low in cost and readily made. See to it that all pipes leading from furnace are sharply slanted upward. Do not allow square end elbows warm-air pipes neutralize to some extent the natural active tendency of warm air to rise and circulate. If the house is long and narrow place the heater as indicated, thus permitting all pipes to be give a sharp upward rise. (See Figs. 3 and 4.) If the ceiling is low set the give upward slant to all pipes as they leave the furnace. Fit a baffle plate as shown in Fig. 3 to extend into furnace. over a greater section of the furnace heating surfaces. As now generally in. stalled, fresh air passes to the upper heating drum, up one side of the furnace in a compact thick body, thus only its outer skin is warmed. This baffle plate will increase the efficiency of this style f heater.

The heating requirements of every by are three distinct methods of applying steam and hot water heat to the home. These are known as the direct-heating. method, direct-indirect-heating method, and the indirect-heating method.

The direct method used with steam or hot water is the least complicated, positive in action, and is very efficient. in is lowest in cost of installation and This method is very easily installed, and there is less heat loss in transmission with this system. Radiators are placed directly in rooms to be heated, and no irect fresh air supply is furnished. is important, however, as previously stated, that a fresh air regulating. ventilator be provided for each room. The loss of space occupied by radiators and the absence of connected ventilators is amply compensated for by the many considered most practical for the average

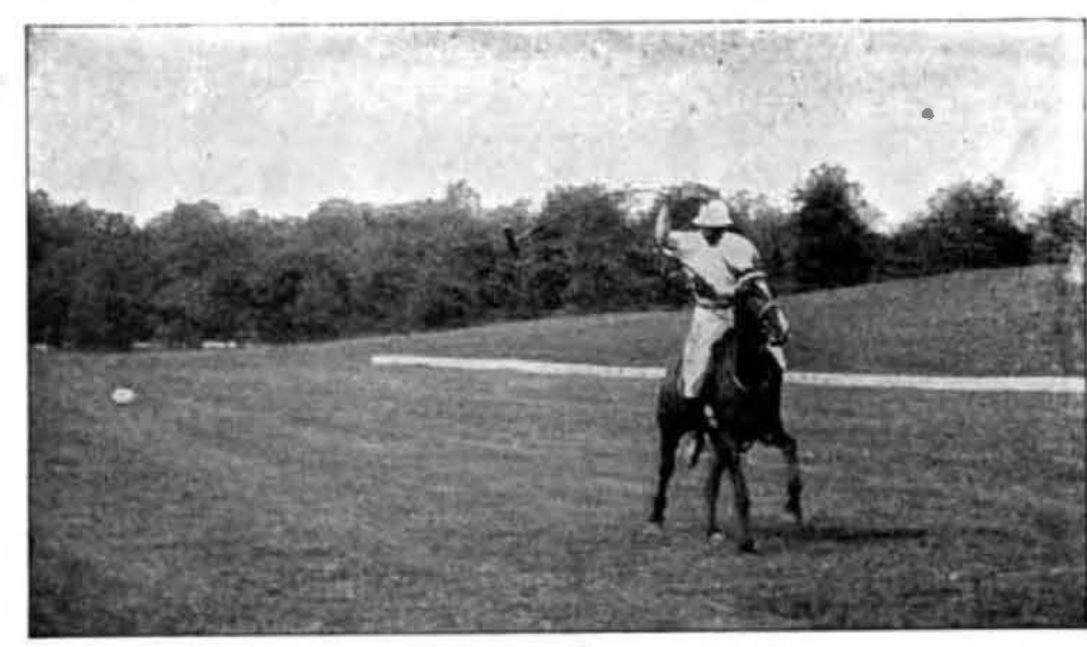

FROM IA SPEED KODAK NEGATIVE,

\section{Get Action}

Speed pictures - pictures of the ninety mile auto, the running horse, birds on the wing, the limited express, snap-shots on cloudy days and even indoors-all these are in the every day work of the new Speed Kodak - the camera that meets the most exacting conditions, yet retains the Kodak convenience.

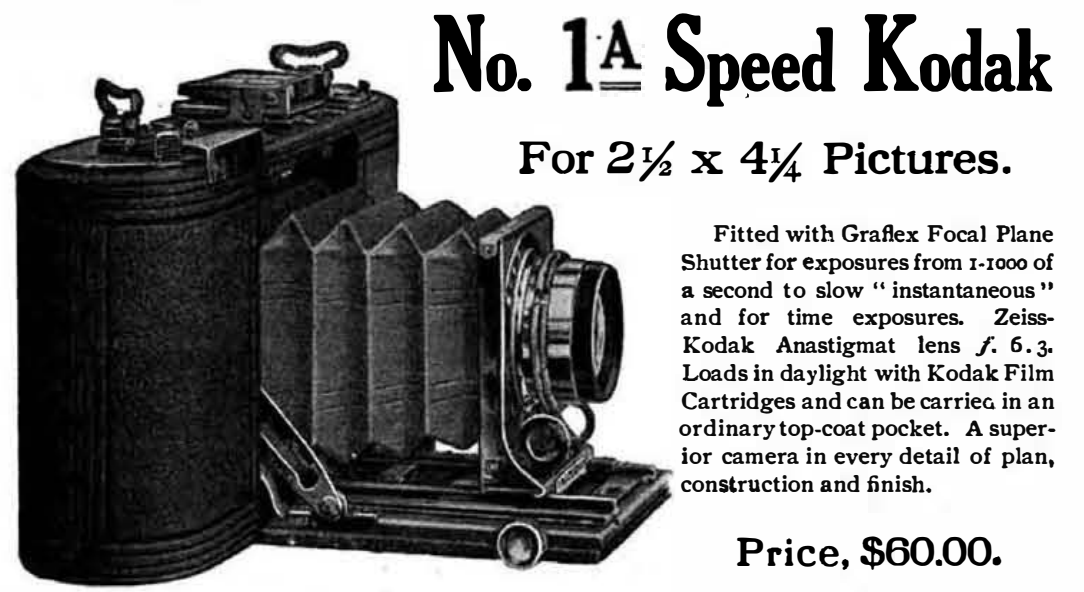

EASTMAN KODAK COMPANY,

Catalogue free at the
dealers orby mail. ROCHESTER, N. Y., The Kodak City.
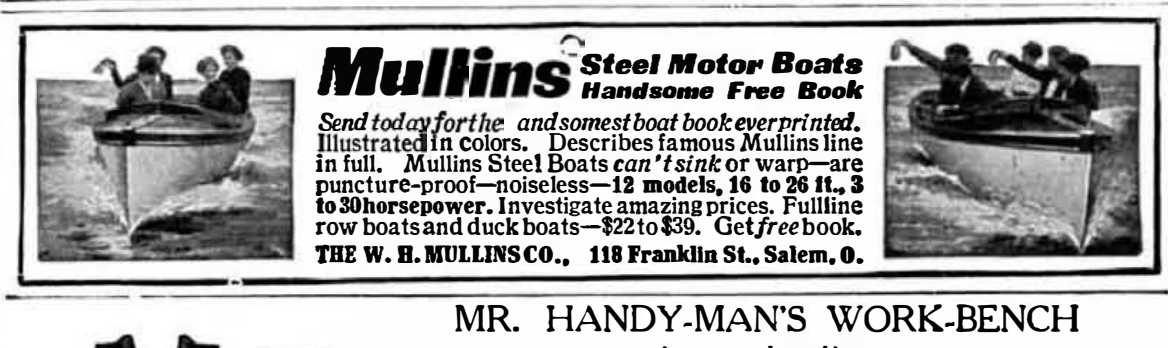

MR. HANDY-MAN'S WORK-BENCH
PARKER'S PRESSED MET AL CLAMP
Replaces the antiquated, cumbersome, wood clamp. For mechanics, Replaces the antiquated, cumbersome, wood clamp. For mechanics, ma$35 \mathrm{c}, 45 \mathrm{c}$, respectively. Mailed post-paid on receipt of price. Special reduction when ordered in quantities. Liberal discount to dealers.

DON'T BUY GASOLINE ENGINES

Until you investigate "THE MASTER WORKMAN," a two-cylnder asoline, kerosene or alcohol single cylinder engines, with greater durability. Costs Less to Buy-Less to Run. Quickly, easily started.
Ving ibration practically overcome. Cheaply mounted on any wagon. It is a combination portable stationary
or traction engine. SEND FOR CATALOGUE. THE TEE Chicago. THIS IS OUR FIFTY-SIXTH YEAR.

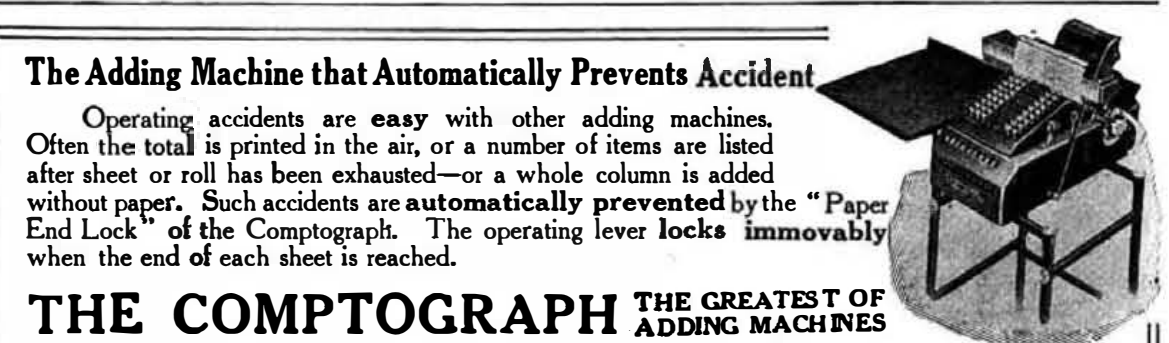

has many other time-saving features. Among them, the Paper Return, by which carriage moves automatically over proper space and rerolls paper ready to write next column; the One
Hand Motion enables operator to turn checks or pages with left hand while operating with right; Perfectly Visible Writing ; and choice of keyboards.

This accident-proof efficiency of the Comptograph added to its greater time-saving improveCOMPTOGRAPH COMPANY 